\title{
ANÁLISE COMPARATIVA DA USABILIDADE ENTRE MODELOS DE LAVADORA DE ROUPA
}

\author{
Marilande Carvalho de Andrade Silva (1); \\ Débora Viviane Albuquerque Granja Santana (2); \\ Janaína Vanessa Laurindo Afonso de Lima (3);
}

Marcelo Márcio Soares (4)

(1) Universidade Federal de Pernambuco, Mestranda em Ergonomia e-mail: marilande andrade@hotmail.com

(2) Universidade Federal de Pernambuco, Mestranda em Ergonomia

e-mail: dviviane@hotmail.com

(3) Universidade Federal de Pernambuco, Mestranda em Ergonomia

e-mail: janaina.alima@ufpe.br

(4) Universidade Federal de Pernambuco, PhD. Em Ergonomia

e-mail: soaresmm@gmail.com

\begin{abstract}
RESUMO
A Ergonomia compreende o estudo do comportamento humano em relação ao seu trabalho, envolvendo conhecimentos científicos relativos ao homem, necessários para a concepção de ferramentas, máquinas e dispositivos visando o máximo de conforto, segurança e eficácia. A usabilidade é um dos componentes da aceitabilidade de um produto e refere-se à habilidade do usuário em poder utilizar suas funcionalidades do na prática. Este estudo teve como objetivo estabelecer uma comparação entre duas máquinas lavadoras de roupas com painéis analógico e digital, analisando a usabilidade percebida pelos seus usuários, sendo identificadas algumas disfunções da Interface Produto Usuário em ambas as máquinas.
\end{abstract}

Palavras-chave: Ergonomia, Usabilidade, Máquinas de lavar

\section{ABSTRACT}

Ergonomics is the study of human behavior in relation to their work, involving scientific knowledge relating to man, required for the design of tools, machines and devices aimed at maximum comfort, safety and efficacy. Usability is one of the components of the acceptability of 
a product and refers to the user's ability to be able to use its features in practice. This study aimed to establish a comparison between two washers machines clothes with analog and digital panels, analyzing usability perceived by its users, identifying some dysfunctions Product User Interface in both machines.

Key Words: Ergonomics, Usability, Washer machines

\section{INTRODUÇÃO}

A Ergonomia é considerada uma disciplina científica relacionada ao entendimento das interações entre os seres humanos e outros elementos do sistema, bem como aplicação da teoria, princípios, dados e métodos ao design, a fim de otimizar o bemestar humano e a melhoria de desempenho do sistema (ASSOCIAÇÃO INTERNACIONAL DE ERGONOMIA, 2000). Essa área do conhecimento compreende o estudo do comportamento humano, em relação ao seu trabalho. Dessa forma, a pesquisa ergonômica é usada na adaptação das condições de trabalho à natureza física e psicológica do homem, e isto resulta no mais importante princípio da Ergonomia: a adaptação da tarefa ao homem (GRANDJEAN, 1984).

A esfera de Produtos envolve um conjunto de conhecimentos científicos relativos ao homem, necessários para a concepção de ferramentas, máquinas e dispositivos que possam ser utilizados com o máximo de conforto, segurança e eficácia (WISNER, 1987). Do ponto de vista ergonômico, os produtos são considerados como meios para que o homem possa executar determinadas funções. Esses produtos passam a fazer parte do sistema homem-máquina-ambiente. Portanto, o objetivo da Ergonomia é estudar esses sistemas para que as máquinas possam funcionar harmoniosamente com o homem, de modo que o desempenho dos mesmos seja adequado (IIDA, 2005).

Como há um consenso no fato de que produtos difíceis de usar não são agradáveis e consequentemente não propiciam satisfação aos usuários, o projeto ergonômico implica na aplicação da informação ergonômica ao design de ferramentas, máquinas, sistemas, tarefas, trabalhos e ambientes para o uso humano seguro, confortável e efetivo (CHAPANIS, 1996). Assim, a satisfação deveria ser considerada tanto no processo de design dos artefatos quanto na sua avaliação, com vistas à melhoria da interação indivíduo-artefato (JORDAN, 2000).

Nesse contexto, encontra-se a Usabilidade, um dos componentes da aceitabilidade de um produto que se refere à habilidade do usuário em poder utilizar as funcionalidades do produto na prática (BETIOL, 2004). Significa eficiência, facilidade, comodidade e segurança no uso dos produtos, tanto no ambiente doméstico como no profissional, incluindo a facilidade de manuseio e fornecimento claro de (IIDA; GUIMARÃES, 2016). Preconiza-se então que, desde o início do projeto, a consideração com a usabilidade deve estar presente e que os produtos devem ser desenvolvidos de modo que a ocorrência desses erros seja minimizada (JORDAN, 1998; MORAES, 2001).

Assim, o conceito de Usabilidade inclui não só os aspectos relacionados ao desempenho durante o uso de um artefato, mas também aspectos subjetivos, como o sentimento de satisfação do usuário com o produto (VASQUES, 2011).

\section{OBJETIVO}

Este estudo teve como objetivo estabelecer uma comparação entre duas máquinas lavadoras de roupa, analisando a usabilidade percebida pelos seus usuários. 


\section{METODOLOGIA}

\subsection{Apresentação dos Produtos:}

Ambas as lavadoras analisadas desempenham as funções básicas para a lavagem de roupa no ambiente doméstico: A) Liga/desliga, B) Lavagem, C) Enxágue + Centrífuga. A máquina $A$ pertence ao modelo Consul Maré da marca Consul (Figura 1), mas não disponibiliza o modo de secagem. Tem capacidade de até $7,5 \mathrm{Kg}$, apresenta cesto de roupas superior e possui um painel analógico. O espaço para depósito dos produtos de limpeza fica posicionado na parte interior da máquina.

Figura 1. Máquina A, modelo Consul Maré com capacidade de $7,5 \mathrm{~kg}$ e painel de controle Analógico

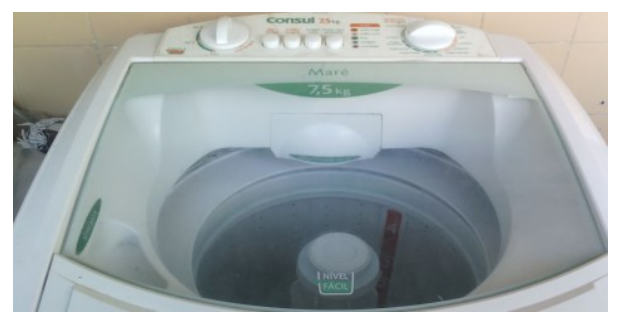

No painel de controle da máquina $A$, há 2 botões giratórios: um para selecionar o nível de água e o outro para selecionar os programas de lavagem, de acordo com os tipos de roupa. Há também botões de liga/desliga, lavagem turbo, enxágue extra e super amaciante. Quando o tipo de lavagem é selecionado, as figuras relacionadas às funções são acesas e vão sendo apagadas ao término de cada processo (lavagemenxágue-centrifugação).

A máquina $B$ pertence ao modelo WD1485ATA da marca LG (Figura 2) e, além das funções básicas, desempenha ainda a função de Secagem. Tem capacidade de até $8,5 \mathrm{Kg}$, tem cesto de roupas frontal e possui um painel digital. O espaço para depósito dos produtos de limpeza fica posicionado na parte exterior do equipamento.

Figura 2. Máquina B, modelo WD1485ATA LG com capacidade de $8,5 \mathrm{~kg}$ e painel de controle Digital

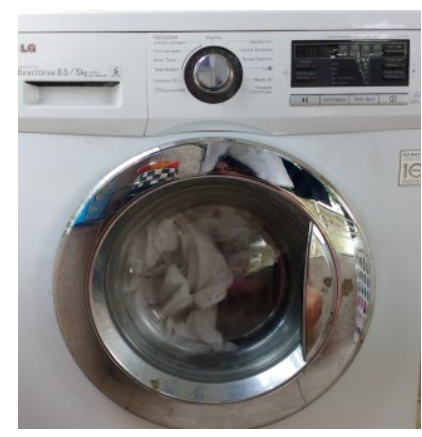

No painel de controle da máquina $B$, há botão giratório para selecionar o tipo de lavagem (de acordo com o tipo de roupa e as funções isoladas de lavagem completa/enxaguar e centrifugar/secagem). O tempo de lavagem é ajustado automaticamente pela própria máquina, de acordo com o tipo de lavagem selecionado. 
Há também um display com um visor de LED à direita do painel que demonstra o tempo estimado de lavagem, a temperatura da água (variando entre fria e $95^{\circ} \mathrm{C}$ ), figuras indicando as funções selecionadas pelo usuário e mensagens sobre o estado da máquina durante o seu uso. Essa máquina é acionada por meio de botões de liga/desliga e play/pause (para iniciar ou pausar o processo de lavagem). O tempo de lavagem é contado regressivamente no display e ao término do processo, a lavadora emite um alarme sonoro. Quando há carga de roupas excedente, este produto também emite um alarme sonoro e demonstra uma mensagem de erro no display.

\subsection{Desenho do Estudo}

Neste estudo foi empregada uma metodologia descritiva e qualitativa, de corte transversal. Na pesquisa descritiva são observados, registrados e analisados os fatos sem que haja manipulação do pesquisador (PRESTES, 2008). A abordagem pretende verificar a relação da realidade com o objeto de estudo, obtendo várias interpretações de uma análise indutiva por parte do pesquisador (RAMOS; RAMOS; BUSNELLO, 2003). Num estudo transversal, os dados são coletados em um ponto no tempo, para descrever as características de uma população num determinado momento (RICHARDSON, 2007).

\subsection{Amostra}

Neste estudo, participaram 6 indivíduos que foram divididos em 2 grupos. O primeiro grupo utilizou uma lavadora com painel analógico (Máquina A) e o segundo grupo utilizou outra lavadora com painel digital (Máquina B). Em cada grupo, os voluntários foram classificados usuários novatos, ocasionais e experientes.

\subsection{Instrumentos de Coleta de Dados}

Para a coleta de dados, foram utilizados os métodos de Verbalização Simultânea, Observação do Usuário e aplicação de um Questionário para verificar a percepção dos participantes sobre usabilidade dos dois produtos que foram comparados.

Para lida (2005), a verbalização requer que o participante descreva o que ele pensa e o que faz enquanto usa um produto. Nesse sentido, ele deve emitir informações sobre os componentes de satisfação de usabilidade. Já a Observação de Campo refere-se a observar o participante utilizando o produto em seu ambiente real. Ainda, o questionário é representado por uma lista impressa de perguntas abertas ou fechadas, as quais o voluntário responde livremente.

\subsection{Procedimentos}

Em momentos distintos, cada usuário foi submetido ao uso da máquina em suas residências, com o intuito de utilizar o programa de lavagem normal em todos os casos. Enquanto faziam o procedimento, foram solicitados a verbalizar as suas ações durante o processo, sendo observados pelas pesquisadoras. Para fazer a Verbalização das atividades, as pesquisadoras coletaram os depoimentos dos usuários enquanto operaram os sistemas, durante o seu uso. Durante a análise individual, os participantes descreveram verbalmente as etapas que seguiram no processo de lavagem. Após a observação do desenvolvimento das tarefas, responderam ao questionário.

\section{RESULTADOS E DISCUSSÃO}


Os usuários que participaram desta pesquisa possuíam faixa etária entre 17 e 55 anos. Quatro deles são do sexo feminino e dois do sexo masculino. O nível de escolaridade variou de ensino médio incompleto ao nível superior. Da amostra selecionada, apenas 03 (três) usuários trabalham fora de casa. Dentre os voluntários, dois deles relataram que utilizam as máquinas de lavar roupas semanalmente, sendo classificados como experientes. Outros dois afirmaram que só usavam o produto esporadicamente (por não serem os principais usuários em suas residências), isto é, são usuários ocupacionais. Por fim, outros dois participantes que foram solicitados a reproduzir o procedimento de lavagem de roupas, nunca o tinham feito e por isso foram classificados como novatos.

Durante a observação da tarefa, constatou-se que todos os usuários iniciam o processo de lavagem colocando as roupas nos respectivos cestos das máquinas. $\mathrm{Na}$ máquina analógica $(A)$, primeiro os voluntários depositaram os produtos de limpeza no recipiente (que fica no interior da máquina), escolheram o nível da água girando uma peça no painel do equipamento, depois o tipo de lavagem (girando outra peça) e na sequência, acionaram o botão para iniciar a lavagem.

Na máquina digital $(B)$, verificou-se que o processo é um pouco mais complexo, devido à variedade de opções oferecida pelo produto. Os participantes também iniciaram colocando as roupas no cesto (que é frontal) e depositaram os produtos de limpeza nos espaços da gaveta (que fica externa). É preciso acionar o botão de "ligar", selecionar o tipo de lavagem girando uma peça, apertar outro botão para selecionar a temperatura da água e por fim acionar outro botão para iniciar a lavagem (play).

A seguir, as figuras 3.1 e 3.2 representam a Análise dos Cenários sobre o processo de lavagem de roupa nas Máquinas A e B, respectivamente.

Figuras 3.1 e 3.2. Análise de Cenário para tarefa de lavar roupa nas Máquinas A e B 

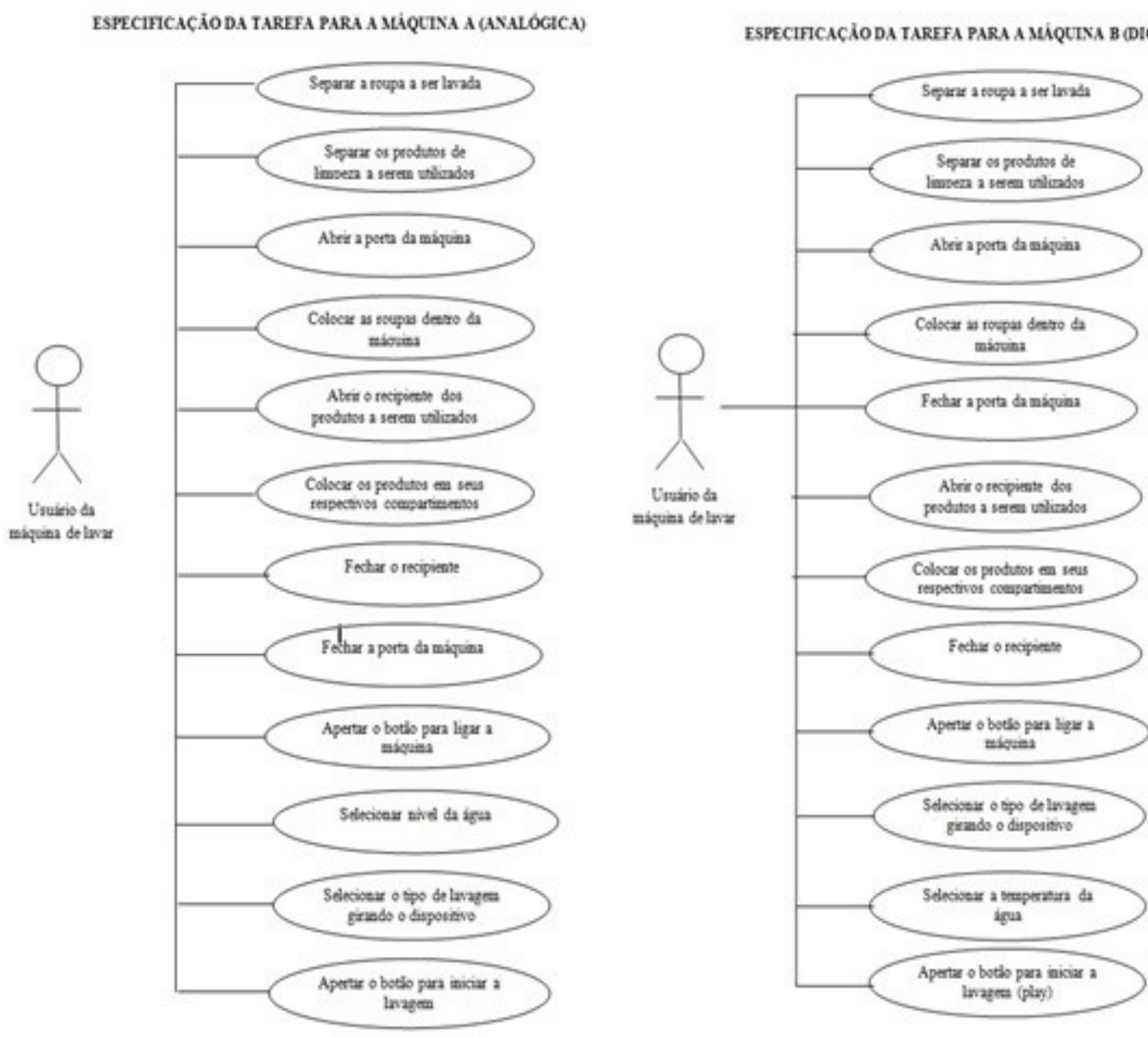

Em relação à máquina $A$, os três usuários selecionados afirmaram que o painel de controle é de fácil compreensão e que o display possui facilidade de leitura, apesar de não terem lido o manual de instruções. No tocante às dificuldades, o usuário novato relatou que não havia um sequenciamento da disposição dos botões no painel de controle, o que induziria ao erro de operacionalidade da máquina. Os três participantes que utilizaram a máquina de lavar com painel analógico estavam satisfeitos com 0 tamanho dos controles (botões e teclas) do equipamento. Todos relataram que o produto atendia as suas expectativas, apesar de alegarem que gostariam de ter uma máquina com outras funcionalidades, como "secagem". Além disso, a referida máquina não possui nenhum dispositivo de comunicação (display) que informe o tempo estimado de duração e término do processo de lavagem. Entretanto, os principais motivos relatados para a escolha do produto $A$ foram o preço e a marca, com o melhor custo benefício. Assim, de acordo com os critérios utilizados, consideram-na o melhor produto a ser adquirido.

Quanto aos usuários da máquina $\mathrm{B}$, com painel digital, também houve respostas positivas em relação ao atendimento das expectativas com o produto. Já quanto à facilidade de compreensão das informações do painel de comando, a usuária novata afirmou ter dificuldades para entender a ordem das funções apresentadas. Apesar de todos os participantes conseguirem visualizar os ícones e palavras no painel e considerarem os botões com um tamanho adequado, esta mesma participante referiu ter tido problemas para compreender a ordem correta para acionar os botões e iniciar a lavagem. Ao ser indagada quanto a função "secagem", a usuária experiente alegou tê-la usado apenas 02 (duas) vezes, pois não compensava, devido ao tempo estimado 
de conclusão do processo todo (5 horas) e também ao alto consumo de energia elétrica.

Após o levantamento obtido a partir das verbalizações e da observação com os usuários, foram listados os principais problemas e possíveis sugestões no quadro abaixo (Figura 4):

Figura 4. Quadro de Análise dos Problemas

\begin{tabular}{|c|c|c|c|c|c|c|c|}
\hline & \multicolumn{7}{|c|}{ FORMULAÇÃO DE PROBLEMAS } \\
\hline & \multicolumn{2}{|c|}{ Problema } & $\begin{array}{c}\text { Requerimento } \\
\mathrm{s} \text { de Design }\end{array}$ & $\begin{array}{l}\text { Problemas } \\
\text { Humanos }\end{array}$ & $\begin{array}{l}\text { Custos } \\
\text { Humanos }\end{array}$ & Sugestões & $\begin{array}{l}\text { Limitações } \\
\text { do sistema }\end{array}$ \\
\hline \multicolumn{8}{|c|}{ INTERFACE } \\
\hline 1 & 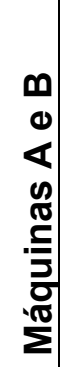 & $\begin{array}{l}\text { Display } \\
\text { não } \\
\text { possui } \\
\text { botões e } \\
\text { dispositi } \\
\text { vo em } \\
\text { braile }\end{array}$ & $\begin{array}{l}\text { Display em } \\
\text { braile }\end{array}$ & $\begin{array}{l}\text { Dificuldade } \\
\text { para } \\
\text { selecionar e } \\
\text { acionar os } \\
\text { comandos } \\
\text { do Display } \\
\text { da máquina }\end{array}$ & $\begin{array}{l}\text { Estresse e } \\
\text { possível } \\
\text { retrabalho } \\
\text { devido a } \\
\text { acioname } \\
\text { nto } \\
\text { incorreto }\end{array}$ & $\begin{array}{l}\text { Adequação } \\
\text { do display } \\
\text { para este } \\
\text { público } \\
\text { específico }\end{array}$ & $\begin{array}{l}\text { Espaço no } \\
\text { painel de } \\
\text { controle } \\
\text { Falta de } \\
\text { interesse } \\
\text { do } \\
\text { fabricante }\end{array}$ \\
\hline 2 & $\begin{array}{c}4 \\
\frac{\pi}{5} \\
\frac{5}{5} \\
\frac{9}{2} \\
\frac{\pi}{2}\end{array}$ & $\begin{array}{l}\text { Falta de } \\
\text { dispositi } \\
\text { vo de } \\
\text { que } \\
\text { informe } \\
\text { o tempo } \\
\text { estimado } \\
\text { de } \\
\text { duração } \\
\text { e } \\
\text { término } \\
\text { do } \\
\text { processo }\end{array}$ & $\begin{array}{l}\text { Mostrador de } \\
\text { tempo dos } \\
\text { processos } \\
\text { e/ou alarme } \\
\text { sonoro }\end{array}$ & $\begin{array}{l}\text { Deslocament } \\
\text { os } \\
\text { constantes } \\
\text { para } \\
\text { monitoramen } \\
\text { to dos } \\
\text { processos }\end{array}$ & $\begin{array}{l}\text { Estresse e } \\
\text { fadiga }\end{array}$ & $\begin{array}{l}\text { Implanta- } \\
\text { ção de } \\
\text { sistema de } \\
\text { controle } \\
\text { temporal } \\
\text { dos } \\
\text { processos }\end{array}$ & $\begin{array}{ll}\text { Espaço no } \\
\text { painel de } \\
\text { controle }\end{array}$ \\
\hline 3 & 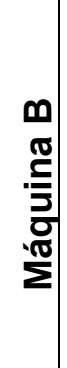 & $\begin{array}{l}\text { Display } \\
\text { não fica } \\
\text { no } \\
\text { campo } \\
\text { de visão } \\
\text { do } \\
\text { usuário }\end{array}$ & $\begin{array}{l}\text { Display } \\
\text { campo } \\
\text { visão } \\
\text { usuário }\end{array}$ & $\begin{array}{l}\text { Agachament } \\
\text { o para } \\
\text { acionar a } \\
\text { máquina }\end{array}$ & $\begin{array}{l}\text { Possível } \\
\text { lesão na } \\
\text { coluna e } \\
\text { joelhos }\end{array}$ & $\begin{array}{l}\text { Adequação } \\
\text { da } \\
\text { localização } \\
\text { do display }\end{array}$ & $\begin{array}{l}\text { Condiciona } \\
\text { mento do } \\
\text { display a } \\
\text { posição do } \\
\text { cesto de } \\
\text { abastecime } \\
\text { nto das } \\
\text { roupas }\end{array}$ \\
\hline
\end{tabular}




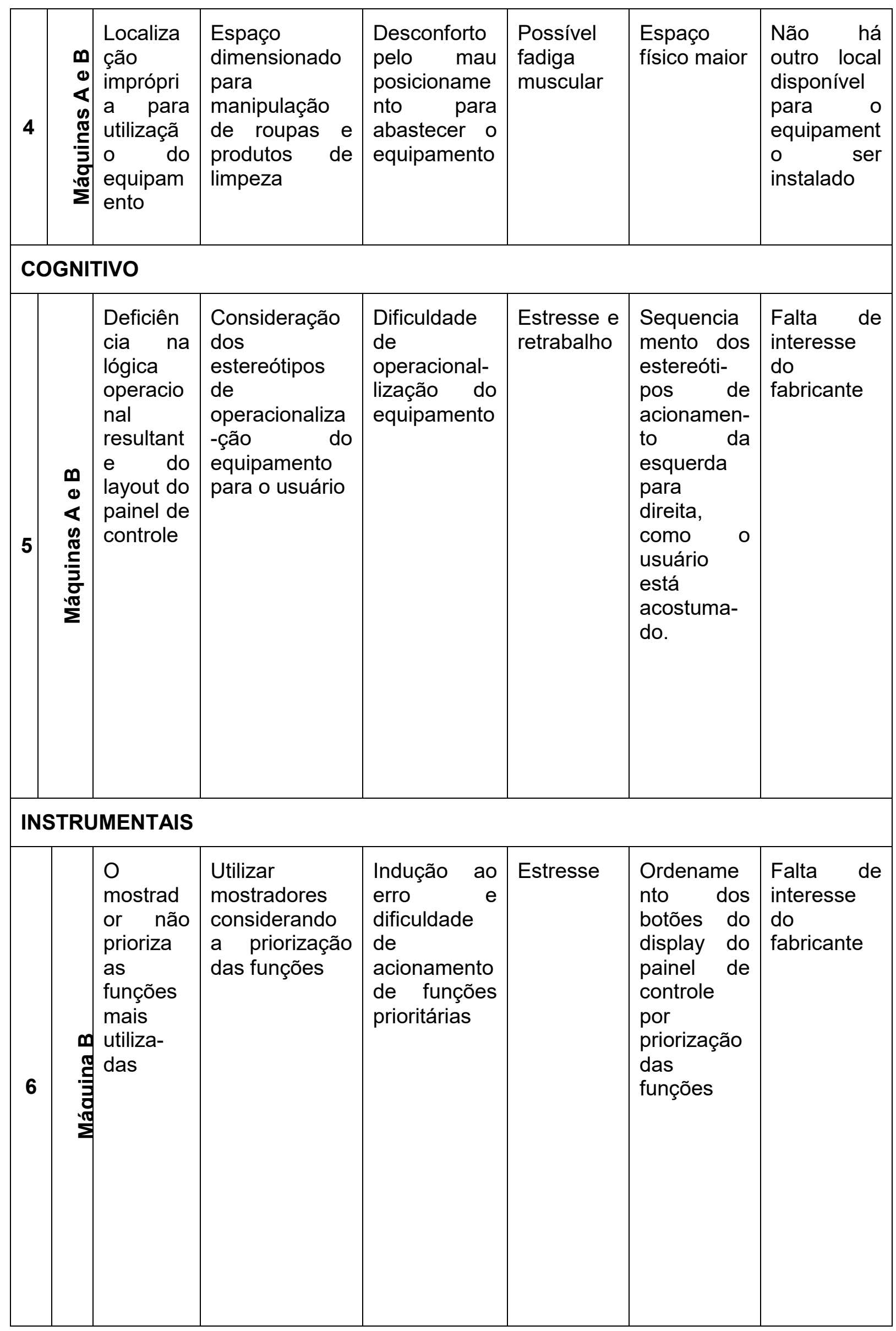




\begin{tabular}{|c|c|c|c|c|c|c|c|}
\hline \multicolumn{8}{|c|}{ CONTROLE } \\
\hline 7 & 鸟 & $\begin{array}{l}\text { O } \\
\text { usuário } \\
\text { tem que } \\
\text { segurar } \\
\text { a tampa } \\
\text { da } \\
\text { máquina } \\
\text { para } \\
\text { mantê-la } \\
\text { aberta e } \\
\text { abastecê } \\
\text {-la }\end{array}$ & $\begin{array}{l}\text { Sistema de } \\
\text { travamento } \\
\text { para abertura } \\
\text { e fechamento } \\
\text { da tampa }\end{array}$ & $\begin{array}{l}\text { O usuário } \\
\text { fica com um } \\
\text { dos braços } \\
\text { constanteme } \\
\text { nte } \\
\text { levantado } \\
\text { enquanto o } \\
\text { outro } \\
\text { abastece a } \\
\text { máquina }\end{array}$ & $\begin{array}{l}\text { Dormênci } \\
\text { a no braço }\end{array}$ & $\begin{array}{l}\text { Implantaçã } \\
\text { o de um } \\
\text { suporte de } \\
\text { travamento } \\
\text { em cada } \\
\text { lado da } \\
\text { tampa para } \\
\text { mantê-la } \\
\text { aberta. }\end{array}$ & $\begin{array}{l}\text { Falta de } \\
\text { interesse } \\
\text { do } \\
\text { fornecedor }\end{array}$ \\
\hline 8 & 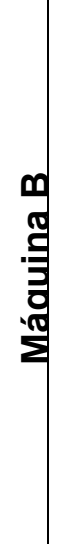 & $\begin{array}{l}\text { A tampa } \\
\text { da } \\
\text { máquina } \\
\text { demora } \\
\text { a destra- } \\
\text { var } \\
\text { depois } \\
\text { de } \\
\text { concluí- } \\
\text { do todo } \\
\text { o processo }\end{array}$ & $\begin{array}{lr}\text { Trava mais } & \text { flexível para } \\
\text { abertura } & \text { do } \\
\text { compartimento }\end{array}$ & $\begin{array}{lr}\text { O } & \text { usuário } \\
\text { "força" } & \text { a } \\
\text { tampa } & \text { para } \\
\text { abrir } & \text { o } \\
\text { compartimen } \\
\text { to } & \text { das } \\
\text { roupas } & \end{array}$ & $\begin{array}{l}\text { Lesionar } \\
\text { dedos/mã } \\
\text { os }\end{array}$ & $\begin{array}{l}\text { Acionamen } \\
\text { to } \\
\text { automático } \\
\text { de trava e } \\
\text { destrava } \\
\text { após o } \\
\text { término de } \\
\text { todo o } \\
\text { processo }\end{array}$ & $\begin{array}{l}\text { Tecnologia } \\
\text { disponível }\end{array}$ \\
\hline \multicolumn{8}{|c|}{ INFORMACIONAL } \\
\hline 9 & $\frac{m}{a}$ & $\begin{array}{l}\text { Alguns } \\
\text { botões } \\
\text { possuem } \\
\text { a função } \\
\text { represen } \\
\text {-tada } \\
\text { apenas } \\
\text { por } \\
\text { símbolos }\end{array}$ & $\begin{array}{l}\text { Botões com } \\
\text { funções } \\
\text { representados } \\
\text { também na } \\
\text { linguagem } \\
\text { escrita }\end{array}$ & $\begin{array}{l}\text { Não } \\
\text { reconhecime } \\
\text { nto ou má } \\
\text { interpretação } \\
\text { das ações } \\
\text { dos botões }\end{array}$ & $\begin{array}{l}\text { Estresse e } \\
\text { retraba- } \\
\text { Ihos }\end{array}$ & $\begin{array}{l}\text { Demonstrar } \\
\text { a função } \\
\text { dos botões } \\
\text { de forma } \\
\text { escrita }\end{array}$ & $\begin{array}{l}\text { Espaço } \\
\text { disponível } \\
\text { do painel } \\
\text { de controle }\end{array}$ \\
\hline \multicolumn{8}{|c|}{ DE MOVIMENTO } \\
\hline $\begin{array}{l}1 \\
0\end{array}$ & $\begin{array}{c}0 \\
0 \\
\frac{0}{a} \\
\frac{7}{3} \\
\frac{0}{2}\end{array}$ & $\begin{array}{l}\text { Peso } \\
\text { excessi- } \\
\text { vo do } \\
\text { produto }\end{array}$ & $\begin{array}{l}\text { Equipamento } \\
\text { mais leve e } \\
\text { com suportes } \\
\text { para facilitar } \\
\text { deslocamentos }\end{array}$ & $\begin{array}{l}\text { Esforço da } \\
\text { coluna para } \\
\text { deslocamen- } \\
\text { to do } \\
\text { equipamento }\end{array}$ & $\begin{array}{l}\text { Dor } \\
\text { lombar e } \\
\text { nos } \\
\text { membros } \\
\text { superiores }\end{array}$ & $\begin{array}{l}\text { Component } \\
\text { es e peças } \\
\text { mais leves, } \\
\text { suporte } \\
\text { para apoio } \\
\text { das mãos e } \\
\text { pés com } \\
\text { rodinhas. }\end{array}$ & $\begin{array}{l}\text { Falta de } \\
\text { interesse } \\
\text { do } \\
\text { fornecedor }\end{array}$ \\
\hline
\end{tabular}


A seguir, estão ilustrados os principais problemas encontrados neste estudo. As figuras 5.1 e 5.2 indicam problemas de Interface e Informacional na Máquina $B$, devido ao display fora do campo de visão e funções representadas apenas por símbolos. Além disso, as figuras 6.1 e 6.2 apresentam problemas Cognitivo e Instrumental referentes à deficiência da lógica operacional resultante do layout dos painéis de controle e à falta de priorização das funções mais utilizadas, na máquina $A$ e $B$, respectivamente.

Figura 5.1 e 5.2 Problemas de Interface e Informacional

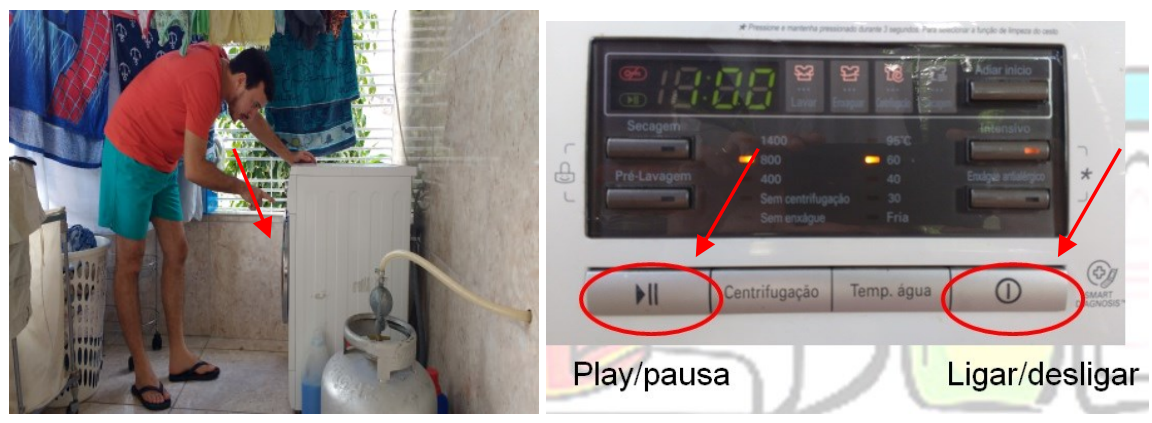

Figuras 6.1 e 6.2 Problema Cognitivo e Instrumental

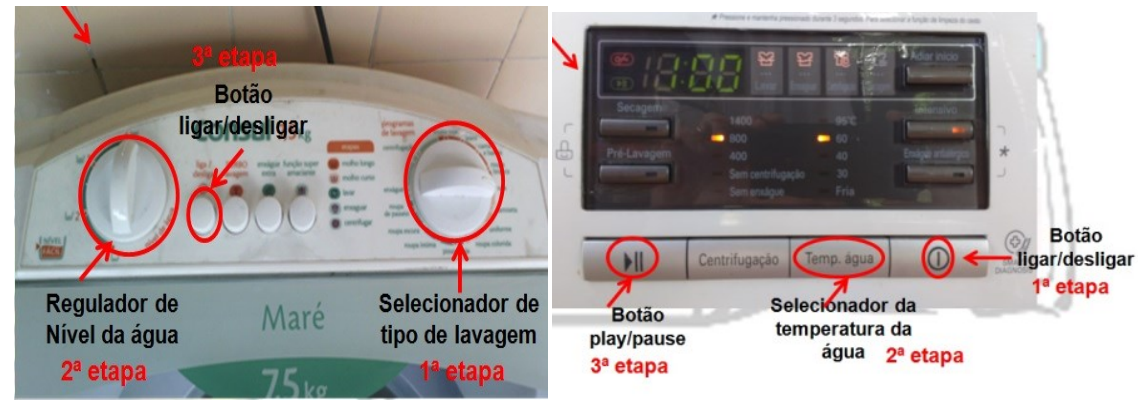

Segundo Bastien e Scapin (1993), a qualidade e a rapidez do feedback são dois fatores importantes para o estabelecimento de satisfação e confiança do usuário. Estes fatores possibilitam que o usuário tenha melhor entendimento do funcionamento do sistema. Além disso, a ausência de feedback ou sua demora podem ser desconcertantes para o usuário. Complementando, Jordan (1998) ressalta que recurso usado com maior frequência pra atender a essa medida é o uso de dispositivos auditivos, recomendado, sobretudo, para a ocasião em que a informação deve receber atenção imediata do operador.

Jordan (1998) alerta que é preciso considerar de que maneira as informações serão repassadas, o tamanho adequado dos caracteres (de modo que facilite a leitura), a quantidade de informações contida em determinado espaço, os tipos de cores para beneficiar a interface e também o local onde as informações serão apresentadas. Nesse sentido, é preferível o usuário detectar erros durante a entrada de dados, do que constatá-lo no resultado final do processo. Ainda, os usuários são capazes de detectar diferentes itens mais facilmente se eles forem apresentados de forma organizada. 
Por fim, lida (2005) refere-se às características cognitivas como os conhecimentos do usuário sobre o modo de usar o produto, baseando-se em suas experiências anteriores. Dessa forma, qualquer produto que contrarie esses estereótipos causará dificuldade.

\section{CONSIDERAÇÕES FINAIS}

A partir da análise comparativa entre as duas lavadoras de roupa, verificou-se que, apesar de ambos os painéis não seguirem uma sequência de estereótipos, os usuários conseguiram realizar o procedimento de lavagem sem maiores problemas. No entanto, pelo fato de a máquina digital possuir mais funcionalidades em seu painel, um usuário novato leva um pouco mais de tempo para cumprir todos os procedimentos, já que precisa analisar atentamente todas as informações contidas no painel, para então tomar uma decisão e acionar os botões desejados.

Apesar de algumas dificuldades relatadas pelos usuários participantes deste estudo, todos se consideraram satisfeitos com suas respectivas máquinas, uma vez que atendiam as suas expectativas e necessidades.

Algumas sugestões apresentadas no quadro de análise dos problemas são relativamente simples e fáceis de aplicar. Acredita-se que elas agregariam valor aos produtos e deixariam os usuários ainda mais satisfeitos. Diante do exposto, considerase viável a aquisição dos dois modelos para os respectivos nichos de mercado.

\section{REFERÊNCIAS BIBLIOGRÁFICAS}

ASSOCIAÇÃO INTERNACIONAL DE ERGONOMIA. XV Congresso Internacional de Ergonomia. São Diego, EUA, 2000.

BASTIEN, J.C.; D.L. SCAPIN. Critérios Ergonômicos para Avaliação de Interfaces HomemComputador. Labiutil. 1993.

BETIOL, A.H. Avaliação de usabilidade para os computadores de mão: um estudo comparativo entre três abordagens para ensaios de interação. 2004. Tese (Doutorado em Engenharia de Produção)- Programa de Pós-graduação em Engenharia de Produção, UFSC, Florianópolis, $210 \mathrm{p}$.

CHAPANIS, A. Human factors in systems engineering. New York: John Wiley \& Sons, 1996.

IIDA, I. Ergonomia: Projeto e Produção. 2.ed. São Paulo: Blucher, 2005.

IIDA, I.; GUIMARÃES, L.B.M. Ergonomia: Projeto e Produção.3.ed. São Paulo: Blucher, 2016.

GRANDJEAN, E. Ergonomics and health in modern office.London, Taylor \& Francis, 1984.

JORDAN, P. W. An introduction to usability. London: Taylor \& Francis, 1998.

P.W..Designing pleasurable products: an introduction to the new human factors.London: Taylor \& Francis, 2000.

MORAES, A.; MELO, C.N.V.; GOMMA, H.S. Ergonomia e Usabilidade: um enfoque heurístico sobre manuais de instrução de dois produtos domésticos. $5^{\circ}$ Ergodesign, Rio 
de Janeiro, 2005. WISNER, A. Textos Escolhidos, antropotecnologia. Rio de Janeiro, Ed. Virtual Científica, 2004.

PRESTES, M.L.M. A pesquisa e a construção do pensamento científico: do planejamento aos textos, da escola à academia. 3. ed. São Paulo: Rêspel, 2008.

RAMOS, P.; RAMOS, M.M.; BUSNELLO, S.J. Manual Prático de Metodologia da Pesquisa: Artigo, Resenha, Projeto, TCC, Monografia, Dissertação e Tese. Blumenau: Acadêmica,2003.

RICHARDSON, R.J. Pesquisa Social: métodos e técnicas.3.ed. São Paulo: Atlas, 2007.

VASQUES, R.A. Design, cultura e sustentabilidade: um estudo sobre o uso compartilhado em lavanderias de edifícios residenciais em Curitiba-PR. 2011. Dissertação (Mestrado em Design) - Programa de Pós-Graduação em Design, Universidade Federal do Paraná.

WISNER, A. Textos Escolhidos, antropotecnologia. Rio de Janeiro: Virtual Científica, 2004. 